\title{
BMJ Open Influence of religious organisations' statements on compliance with a smoke-free law in Bogor, Indonesia: a qualitative study
}

\author{
M Justin Byron, ${ }^{1,2}$ Joanna E Cohen, ${ }^{3}$ Joel Gittelsohn, ${ }^{4}$ Shannon Frattaroli, ${ }^{5}$ \\ Ramadhani Nuryunawati, ${ }^{6}$ David H Jernigan ${ }^{7}$
}

To cite: Byron MJ, Cohen JE, Gittelsohn J, et al. Influence of religious organisations' statements on compliance with a smoke-free law in Bogor, Indonesia: a qualitative study. BMJ Open 2015;5:e008111. doi:10.1136/bmjopen-2015008111

- Prepublication history for this paper is available online. To view these files please visit the journal online (http://dx.doi.org/10.1136/ bmjopen-2015-008111).

Received 5 March 2015 Revised 10 October 2015 Accepted 15 October 2015

CrossMark

For numbered affiliations see end of article.

Correspondence to Dr M Justin Byron; jbyron@unc.edu

\section{ABSTRACT}

Objective: To explore the Bogor public's perspective on Muslim organisations' pronouncements against smoking and the effect of these pronouncements on compliance with a new smoke-free law in the context of a prosmoking social norm.

Design: Semistructured focus group discussions were conducted, transcribed, coded using ATLAS.ti software, and analysed using thematic content analysis. Photo elicitation was also used during the focus groups.

Setting: Bogor, Indonesia.

Participants: 11 focus groups $(n=89)$, stratified by age, gender and smoking status, with members of the public (46 male, 43 female, ages 18-50).

Results: There was limited knowledge of and compliance with both the smoke-free law and the religious pronouncements. In most of the focus groups, smoking was described as a discouraged, but not forbidden, behaviour for Muslims. Participants described the decision of whether to follow the religious pronouncements in the context of individual choice. Some participants felt religious organisations lacked credibility to speak against smoking because many religious leaders themselves smoke. However, some non-smokers said their religion reinforced their non-smoking behaviour and some participants stated it would be useful for religious leaders to speak more about the smoke-free law.

\section{Conclusions: Religious organisations'}

pronouncements appear to have had a small effect, primarily in supporting the position of non-smokers not to smoke. Participants, including smokers, said their religious leaders should be involved in supporting the smoke-free law. These findings suggest there is potential for the tobacco control community to partner with sympathetic local Muslim leaders to promote common goals of reducing smoking and public smoke exposure. Muslim leaders' views on smoking would be perceived as more credible if they themselves followed the smoke-free law. Additionally, public health messaging that includes religious themes could be piloted and tested for effectiveness. These findings may also inform similar efforts in other Muslim cities implementing smoke-free laws.

\section{Strengths and limitations of this study}

- This is the first study to explore the effect of religious organisations' pronouncements about smoking on the public's views about compliance with a smoke-free law. This question is especially important in low-income and middle-income countries where governments may have fewer resources for education and enforcement.

- The use of semistructured focus groups with everyday Bogor residents allowed for the collection of rich insight into the complexities of religious, legal and social norms around public smoking.

- The focus groups were stratified by gender, age and smoking status, allowing for more open dialogue among participants.

- The use of a convenience sample may limit transferability of the findings.

- Since the data analysis was conducted using translated data, some nuances of language and culture may have been missed.

\section{INTRODUCTION}

In the past 20 years, Muslim leaders and organisations worldwide have become more outspoken against tobacco use. ${ }^{1}{ }^{2}$ Their fatwas (religious rulings or opinions) forbidding smoking combined with other tobacco control efforts may help reduce smoking prevalence and reinforce emerging secular smoke-free laws that restrict smoking in public spaces. ${ }^{2-5} \mathrm{~A}$ number of studies have shown associations between religiosity and reduced smoking prevalence ${ }^{6}$ and potential benefits of religion-based tobacco control interventions. $^{7-9}$ In Malaysia, a majority Muslim country where male smoking is generally perceived as socially acceptable, religious norms have been shown to play a greater role than secular norms in influencing quit attempts. ${ }^{10}$ These findings are 
Table 1 Positions of major Muslim bodies in Indonesia

\begin{tabular}{|c|c|c|c|}
\hline Name & Type & Members & Decree on smoking (year) \\
\hline $\begin{array}{l}\text { Majelis Ulama } \\
\text { Indonesia (MUI) }\end{array}$ & $\begin{array}{l}\text { Muslim leadership } \\
\text { body }\end{array}$ & $\sim 700^{17}$ & $\begin{array}{l}\text { Smoking by children and pregnant women and smoking in } \\
\text { public is haram (forbidden); otherwise smoking is makruh } \\
\text { (discouraged) (2009) }\end{array}$ \\
\hline Muhammadiyah & Muslim organisation & 30 million $^{25}$ & All smoking is haram for its followers (2010) \\
\hline Nahdlatul Ulama (NU) & Muslim organisation & 40 million $^{25}$ & All smoking is makruh (2009) \\
\hline
\end{tabular}

consistent with social norms research showing that people are most likely to be influenced by groups with which they closely identify. ${ }^{11}$ According to reference group theory, the degree to which a group serves as an influential reference point for an individual is a function of five factors: similarity in status to the group, sharing the values and beliefs of the group, having clarity about the group's values and beliefs, having sustained interaction with the group, and whether an individual defines other group members as significant. ${ }^{12-14}$ This theory is readily applicable to understanding religious influences on smoking behaviour. ${ }^{14}$ Smokers who identify with a particular religion may look to their religion as their reference group rather than society at large, making religious leaders potentially powerful figures in the success of smoke-free laws. ${ }^{14}$ The WHO encourages working with religious leaders in tobacco control efforts. $^{15}$ However, most investigations regarding smoking and religion have focused on Christianity in high-income countries. ${ }^{6}$ The current study explored religion and smoking in the predominantly Muslim $(87 \%)$ country of Indonesia (population 238 million). ${ }^{16}$

Islam has a strong legal tradition that works to minimise harm to society and individuals. ${ }^{2}$ All human affairs are classified as fard (mandatory), mustahabb (encouraged), mubah (neutral), makruh (discouraged, not sinful but those abstaining from it will be blessed by God) or haram (prohibited). In January of 2009, Majelis Ulama Indonesia (MUI), the government-funded council in Jakarta that includes representation from many Indonesian Muslim organisations, issued a fatwa classifying smoking in public and smoking by children or pregnant women as haram (table 1). ${ }^{17}$ Otherwise smoking was said to be makruh. Among the members of the MUI council are representatives of Indonesia's two dominant social and religious organisations, which oversee thousands of Muslim schools, clinics and hospitals. At the time, Nahdlatul Ulama (NU), the larger of these organisations, disagreed with the MUI fatwa, saying, "the danger of smoking is relative, not as significant as the danger of drinking [alcohol]. Also, those who smoke have relative benefit, for example, their thinking is clear when smoking." 18 (Recently, NU has become more open to tobacco control, as evidenced by its prohibition on smoking within some of its venues. ${ }^{19}$ ) In March 2010, Muhammadiyah, the other large Muslim organisation, declared all smoking haram for its followers, citing the
Quran's prohibition on suicide, ${ }^{20}$ "make not your own hands contribute to your own destruction $(2 ; 195){ }^{2}$ Other Muslim scholars have additionally cited the Quran's statements against causing wilful harm or annoyance to others. ${ }^{12}$

Indonesia is a country struggling with a large and growing tobacco problem. With 61.4 million smokers, Indonesia is third only to China and India in number of smokers. ${ }^{21}$ Between 1995 and 2011, smoking rates rose from $54 \%$ to $67 \%$ among men and from $1.7 \%$ to $4.5 \%$ among women. ${ }^{21}$ Additionally, the clove cigarettes (kreteks) that comprise most of Indonesian tobacco consumption (92\%) may be more toxic than tobacco-only cigarettes. $^{22}$ Smoking in public places in Indonesia is common: $51 \%$ of adults are exposed to tobacco smoke in the workplace, and $85 \%$ of restaurant-goers are exposed to smoke in restaurants. ${ }^{21}$ There is limited public awareness of the risks of secondhand smoke, especially among smokers, older adults and less-educated populations. ${ }^{21}$

At the national level, Indonesia has minimal tobacco control measures and is one of the few countries that have not signed the WHO Framework Convention on Tobacco Control. However, some progress is being made in Indonesia's cities. Bogor, a city of one million people located $50 \mathrm{~km}$ south of Jakarta, was the first Indonesian city to pass a comprehensive smoke-free law, restricting tobacco smoking in most public spaces. Bogor is in a province that is $97 \%$ Muslim. $^{16}$ The 2009 law, which took effect in May 2010, banned smoking in all hotels, restaurants, public markets, malls, places of worship, workplaces, playgrounds, schools, health facilities and public transportation. ${ }^{23}$ The city does not allow indoor designated smoking areas or exemptions. An evaluation in early 2011 found that overall $87 \%$ of venues were free of smoke, but there was still smoking in $84 \%$ of traditional markets, $43 \%$ of restaurants, $29 \%$ of government buildings and $11 \%$ of places of worship. ${ }^{24}$

To our knowledge, this is the first study to examine how religious antismoking pronouncements influence the public's perspectives about smoke-free laws. If the messages are influential, the tobacco control community may benefit from a partnership with religious organisations. This manuscript explores the role of smoking in Indonesian religion and society, what Bogor's residents think about the religious status of smoking and smoking in public, and how the fatwas affect compliance with the smoke-free law in Bogor. 
Table 2 Focus group participants

\begin{tabular}{|c|c|c|c|c|}
\hline Gender and smoking status & Ages recruited & Recruitment venue & Number recruited & Number attended \\
\hline Male smokers & $18-25$ & Mall & 12 & 10 \\
\hline Male smokers & $18-25$ & Mall & 10 & 9 \\
\hline Male smokers & $26+$ & Mall & 12 & 8 \\
\hline Male smokers & $26+$ & Mall & 10 & 5 \\
\hline Male smokers & $18+$ & Market & 10 & 7 \\
\hline Male non-smokers & $18+$ & Mall & 10 & 7 \\
\hline Female smokers & $18+$ & Mall & 10 & 8 \\
\hline Female non-smokers & $18-25$ & Mall & 12 & 10 \\
\hline Female non-smokers & $26+$ & Mall & 9 & 7 \\
\hline Female non-smokers & $26+$ & Mall & 10 & 10 \\
\hline \multirow[t]{2}{*}{ Female non-smokers } & $18+$ & Market & 10 & 8 \\
\hline & & & 115 & 89 \\
\hline
\end{tabular}

\section{METHODS}

In July 2012, 11 semistructured focus groups were conducted with residents of Bogor. Participants were recruited from a shopping mall frequented by middleclass Bogor residents and an outdoor market where lower income Bogor residents shop. Shopping areas were chosen because they are safe, accessible public spaces that provide access to a diverse sample of the population. To encourage participants to speak freely, focus groups were stratified by age, gender and smoking status. Five local researchers were trained in recruitment and focus group facilitation. The focus groups were held in rented rooms within public venues and were conducted in Bahasa Indonesia, the national language. Facilitators followed a focus group guide structured around the research questions. Photo elicitation was also used, ${ }^{26}$ by having participants comment on the appropriateness and legality of smoking in public places depicted in five photographs. Participants were provided with snacks and compensation (81 000 rupiah, about \$8.67) for their time. The facilitators transcribed the focus group recordings. Professional translators then translated the transcripts into English, and an additional professional translator checked the translations for thoroughness and accuracy.

Focus group transcripts were iteratively coded in ATLAS.ti V.7.0 qualitative analysis software (ATLAS.ti $\mathrm{GmbH}$, Berlin) using a thematic content analysis strategy, ${ }^{27}$ seeking both recurrent themes and variations in responses to the questions. The lead author (MJB) developed the codebook and assigned the codes, noting emergent themes. MJB had some assistance from RN and other Indonesian colleagues in understanding the findings within the context of Indonesian language and culture. With the recurring responses, we approached saturation around our research questions. ${ }^{27}$ To increase credibility, we triangulated the focus group findings with data collected from interviews with venue managers and city leaders that were part of the larger research project. $^{28}$ In triangulation, multiple data sources are used on the assumption that findings are more credible if they are consistent. ${ }^{27} \mathrm{MJB}$ also searched for negative cases within the data, and we present examples of these within the results where relevant. ${ }^{29}$

\section{RESULTS}

In all, 89 adults (46 male and 43 female) ranging in age from 18 to 50 participated in the 11 focus groups (table 2). Of these, 87 self-identified as Muslim, including one who identified as a member of the religious group Muhammadiyah. Two participants declined to provide their religion. The focus group discussions averaged $126 \mathrm{~min}$ (range $81-160 \mathrm{~min}$ ) in length. While we did not see differences in responses by age group, gender played a central role. The three primary themes that emerged were: (1) public smoking is a cultural norm for Indonesian men and the smoke-free law is only partially effective, (2) opinions vary about the religious acceptability of smoking and about the credibility of religious leaders to speak about tobacco use, and (3) decisions about following religious pronouncements about smoking are often described in terms of individual choice.

\section{Role of smoking in Indonesian religion and society}

Participants described smoking as a normal part of secular and religious Indonesian life, with smoking and smoke exposure frequent in both public and private spaces. Cigarettes are commonly offered alongside traditional snacks and beverages in meetings, funerals, weddings and other religious events. As one male smoker explained:

If it is in our culture that it is a habit to smoke after eating, drinking coffee and smoking, drinking tea and smoking, and reading Quran and smoking-I don't know for the smoking when it is stated as haram by MUI or maybe KTR perda [the local smoke-free law]-but if from the surrounding people [we] have this negative culture, to stop smoking is difficult.

The focus groups revealed that smoking is normative for Indonesian men. Smoking is often portrayed as a 
part of manhood, and men who do not smoke risk being mocked as banci (transvestites), implying they are effeminate and atypical. However, the male non-smokers reframed smoking as contrary to the masculine ideal: "a gentleman is healthy and responsible to his family. He is not a gentleman if he coughs all the time." The social norm for women is not to smoke and women who smoked described feeling ashamed to be seen doing so in public. They saw themselves as not being pious: "since we wear hijab [Muslim headscarf] it's embarrassing to not behave accordingly." To avoid this stigma, some women refrained from smoking in public entirely, while others said they would only smoke in public if they were with other smoking women. A focus group facilitator later explained to us a common 'code' that a woman smoking alone is viewed by others as a prostitute soliciting customers.

The smoke-free law had only been partially effective in changing the social acceptability of indoor public smoking. Participants described uncertainty about where the law applied, and said that the law was rarely enforced. Some of the non-smoking women were frustrated about this lack of enforcement while others took some of the responsibility on themselves: "it is our shared responsibility, not only the government's responsibility."

Some of the smokers we talked with explained that they try not to bother people with their smoke. Non-smokers, and even a few smokers, told of how they had admonished people for smoking in air-conditioned venues or around children or pregnant women. One non-smoker explained his perspective on seeing someone smoke around others: "I thought in my mind, this person is dzalim [Islamic term meaning evil because they hurt people on purpose]. There are women, children, but they smoke as they like. That is dzalim. That is a big sin."

\section{Perceptions of Bogor's residents about the religious status of smoking and smoking in public}

Nearly all participants who expressed an opinion about the Islamic status of smoking said that smoking is makruh (discouraged); a few others said it was haram (forbidden). Participants explained how the message they received regarding smoking could depend on the type of ustad (Muslim cleric or teacher):

Among conventional ustads, it is difficult. They will ask to which verse we refer. They are very fluent in Quran verses. The modern ustads, even though it is not stated explicitly in the verse, they think that if we do something that does not benefit us, it is haram.

Participants considered Muslim leaders' positions along with their own interpretations. Notably, no smoker said they believe smoking is always haram. One woman, a smoker, explained her opinion: "...there was a religious leader who said smoking was haram. But, I think it is more makruh," while others spoke about the status of smoking as a fact, for example, "smoking is not haram, it is makruh," perhaps indicating differences in how subjective they consider Muslim law. One male smoker had a more nuanced perspective, one which fit well with MUI's fatwa and Bogor's smoke-free law: "now, actually smoking is not haram, it is makruh. Only haram when it is in public places because the smoke, the smell, and flavor may cause people who do not smoke to experience difficulty in breathing and coughing." Another said that smoking is acceptable in moderation in Islam, but that if a smoker gets sick, they should reduce their smoking: "It is alright but when it is too much it will cause diseases, now [quoting Quran:] 'everything that tortures our body, ourselves, is haram' only if it is already too much. After it causes diseases, we have to reduce." Non-smokers were more amenable to smoking as being haram. Among non-smokers, some cited their religion as one reason among many for not smoking; as a woman explained:

The religion said it is not allowed, the law said so too... maybe, excuse me, my family, errr...very obedient...So it is like this, religion said no, law said no, doctor said no. You see...so I really obey them.

One male non-smoker framed his perspective on smoking in religious terms: "people who smoke are people who have not received hidayah [Islamic term meaning enlightenment]."

Participants commonly expressed that it was not credible for Muslim leaders to talk negatively about smoking, as many of these leaders themselves smoke. When one focus group was asked if they had heard religious leaders forbidding smoking, a woman said, "No, because ustad is identical to cigarette," which prompted laughter from the other participants. In another group, a participant said, "even though he is the leader, he can only talk, but cannot implement it for himself." Additionally, participants talked about seeing Muslim school leaders and Muslims who had been to Mecca (and were thus seen as Muslim exemplars) who smoked, and noted that smoke-free signage at mosques is often ignored.

\section{Impact of religious pronouncements on compliance with the smoke-free law in Bogor}

When participants were asked whether they perceived that the religious leaders' statements influenced other people, common responses included "it is an individual matter" or "depends on the individual, personally." One male smoker explained that his first reaction to hearing about the city's smoke-free law was, "What is this, prohibiting this and that? At that time, my thought was "your religion is for you, my religion is for me'." although he later came to see the law as 'fair' (adil). While most smokers said they were unaffected by religious pronouncements, others said these messages are important 
and useful. Some people expressed that the local Muslim leaders could have some influence:

But in my opinion when ustad says 'A' [i.e., something], he is more probably to be heard than the Mayor's local regulation. Even the President's rule is not as strong as the ustad saying. The problem is that very rarely ustad says that smoking is haram. 1,000 to 1 , very rare because there is no explicit verse that forbids smoking, that's what they say.

Regarding the smoke-free law, one of the smokers said, "I would like to add that in addition to NGOs, the health office, this should be supported by religious leaders. There is an impact."

Thus, smoking is normative for men, the religious pronouncements have had limited influence to date on what is perceived to be an individual's decision, and according to some participants religious leaders could positively influence compliance with the smoke-free law.

\section{DISCUSSION}

This is the first study to investigate the effect of religious organisations' pronouncements about smoking on the public's views about a smoke-free law. The Indonesian fatwas and the implementation of Bogor's smoke-free law occurred within the context of a largely prosmoking social landscape in which two-thirds of men smoke. Our finding that smoking was normative for men but not women is common for Islamic ${ }^{2}$ and Southeast Asian ${ }^{30}$ countries. We found that the social and religious norms were generally unaffected by the smoke-free law, partially because enforcement was lax. However, there was a general desire to be respectful of others, and people were willing to ask smokers not to smoke around children or pregnant women.

When we asked participants about their understanding of the Muslim position on smoking, most said it was makruh, a few said it was haram, and others were uncertain. The MUI's fatwa against public smoking carried little weight. For smokers, one reason the message of smoking being haram is not more widely accepted may be cognitive, as smokers may be discounting messages that are dissonant with their behaviour. ${ }^{14}$ Reference group theory provides additional insight into why the fatwas are not exerting more influence over the population. Individual Muslims in Bogor show status similarity, likely have similar values and have sustained interaction with the Muslim community, but there were mixed findings as to how significant individuals deem Muslim leaders' pronouncements. On matters of smoking, people saw leaders who smoked as not credible. Additionally, individuals have received differing messages about the acceptability of smoking from various local and national religious leaders. This lack of clarity is also predicted to reduce the groups' influence on individuals. Reference group theory suggests that the MUI's influence could be increased by addressing the smoking leaders' lack of credibility on smoking and seeking out a more uniform Muslim message on smoking. Tobacco control advocates can make the case that things that are makruh truly should be discouraged rather than accepted as normal. Although the traditionalist ustads may not agree that all smoking is haram, they would at least agree that it is makruh, and perhaps would support an indoor smoking ban on the grounds of not harming or annoying other people. An ustad who is explicit that he only smokes outdoors could have credibility regarding smoke-free laws. Local ustads may have more influence than national organisations.

The refrain of 'it depends on the individual' as to whether to follow religious leaders' pronouncements on smoking was somewhat unexpected as Indonesian culture is collectivist and Islamic culture is both collectivist and proscriptive. However, this sentiment fits with the view among scholars that Islam in Indonesia is especially moderate and tolerant. ${ }^{31}$ Muslims in Bogor vary in their religious observances (eg, daily prayer, wearing of hijabs) and are tolerant of these differences in practice. However, local Muslim leaders do appear to have some influence and to have had some impact on smoking perceptions and behaviours. The fatwas have supported nonsmokers in their non-smoking behaviour and desire for smoke-free air, and at least some smokers said that fatwas influence their decisions on smoking. These findings are similar to research among Malaysian Muslims, of whom $30 \%$ agreed that antismoking messages from their religious leaders would motivate them 'a lot' to quit smoking. ${ }^{14}$ Smokers in our focus groups were reflective about the appropriate places and settings for smoking and did not want to disturb people around them. Religious and city leaders could build on the smokers' desire to be respectful along with the public's willingness to socially enforce the law. Efforts to increase social enforcement of the law may make up for the city's sparse legal enforcement. As noted earlier, research in neighbouring Malaysia suggests that where secular norms are not strongly against tobacco, a religious norm restricting tobacco use can be powerful. ${ }^{10}$ In Bogor, public health officials could talk more with local Muslim leaders about supporting the smoke-free law and the importance of the example set by the Muslim leaders. Religious leaders can explain to their members that the MUI fatwa and the city law do not forbid all smoking, but they do forbid it in indoor public places. Both for religious and legal reasons, ustads should strictly enforce the smoke-free law on mosque grounds, and doing so could improve their credibility when speaking about smoking.

\section{Limitations}

The focus group participants were recruited using a convenience sample, and therefore transferability of the findings may be limited. However, we did stratify the groups to gather a diversity of perspectives, and we approached saturation, with few new findings in the later focus groups. A measure of religiosity could have 
told us more about our sample population. Noting the limited age range of participants, we considered additional recruitment focused on adults over age 50, but were limited by the timeline and resources of the study. In addition, we did not talk with local ustads. Such conversations would likely have been helpful to our understanding of how and why the MUI fatwa has not had more of an impact, and how local and national Muslim leaders interact. Finally, the data analysis was conducted using translated data, and nuances of language and culture may have been missed, although this was mitigated by regular communication with the facilitators and translators during the analysis phase about unclear phrasings and cultural references.

\section{Future work}

Our research provides indication that the effects of the Indonesian fatwas alone are limited. Similarly, in Egypt simply being aware of a fatwa against smoking did not affect smoking behaviour. ${ }^{3}$ The public health community may need to focus on recruiting willing local religious leaders, who may be more influential, to support smoke-free laws. Both public health and religious leaders have the shared goal of bettering the well-being of their constituencies. ${ }^{15}$ In cities where smoke-free laws are not adhered to by the public, surveys could be conducted to measure people's awareness of the positions of their religious leaders and their interest in hearing local religious leaders speak more on the issue of tobacco use. Additionally, interviews could be conducted with ustads to understand their perspective. Qualitative and quantitative studies could also explore the influence of religious organisations' statements on public perceptions about tobacco harm reduction policies. Where culturally acceptable, it may be worthwhile to pilot test health messages that cite religious justifications for following smoke-free laws. Messages could suggest that good Muslim men are responsible and do not smoke near others, ${ }^{32}$ and that all parents should speak up to smokers to protect their children from smoke. Another line of inquiry could look at whether findings are similar in settings where waterpipe is the dominant form of tobacco use, as waterpipe may have different usage patterns and cultural and social meaning than kreteks.

\section{CONCLUSION}

The MUI and Muhammadiyah fatwas about smoking have had limited impact in Bogor, and appeared to function mostly in reaffirming non-smokers in their not smoking. However, religious normative influences were apparent and participants said they would like their religious leaders to talk more about the smoke-free law. These findings suggest the need for further research and experimentation in how tobacco control officials can work with religious communities on shared goals of public well-being. In countries where there are limited resources for smoke-free law education and enforcement, religion-backed and socially enforced smoke-free norms may be a valuable supplement.

\section{Author affiliations}

${ }^{1}$ Lineberger Comprehensive Cancer Center, University of North Carolina at Chapel Hill, Chapel Hill, North Carolina, USA

${ }^{2}$ Department of Health Behavior, Gillings School of Global Public Health, University of North Carolina at Chapel Hill, Chapel Hill, North Carolina, USA ${ }^{3}$ Department of Health, Behavior and Society, Institute for Global Tobacco Control, Johns Hopkins Bloomberg School of Public Health, Baltimore, Maryland, USA

${ }^{4}$ Department of International Health, Johns Hopkins Bloomberg School of Public Health, Baltimore, Maryland, USA

${ }^{5}$ Department of Health Policy and Management, Johns Hopkins Bloomberg School of Public Health, Baltimore, Maryland, USA

${ }^{6}$ Independent Researcher, Bogor City, Indonesia

${ }^{7}$ Department of Health, Behavior and Society, Johns Hopkins Bloomberg School of Public Health, Baltimore, Maryland, USA

Acknowledgements The authors would like to thank the Bogor City Health Department, No Tobacco Community, and the International Union Against Tuberculosis and Lung Disease for their logistical and advisory support during the fieldwork for this project. They also thank their Indonesian research colleagues.

Contributors MJB led project design, data collection, analysis and writing. DHJ, JEC, JG and SF assisted with project design, data collection oversight, revising and final review. RN assisted with data acquisition and interpretation, revising, and final review.

Funding This study was supported by an award from the Institute for Global Tobacco Control at the Johns Hopkins Bloomberg School of Public Health with funding from the Bloomberg Initiative to Reduce Tobacco Use.

Competing interests None declared.

Ethics approval The study was approved by the City of Bogor and the Institutional Review Boards of the Johns Hopkins Bloomberg School of Public Health and the University of Muhammadiyah Yogyakarta.

Provenance and peer review Not commissioned; externally peer reviewed.

Data sharing statement No additional data are available.

Open Access This is an Open Access article distributed in accordance with the Creative Commons Attribution Non Commercial (CC BY-NC 4.0) license, which permits others to distribute, remix, adapt, build upon this work noncommercially, and license their derivative works on different terms, provided the original work is properly cited and the use is non-commercial. See: http:// creativecommons.org/licenses/by-nc/4.0/

\section{REFERENCES}

1. Khayat $\mathrm{MH}$, ed. Islamic ruling on smoking. Alexandria, Egypt: World Health Organization, Regional Office for the Eastern Mediterranean, 2000.

2. Ghouri N, Atcha M, Sheikh A. Influence of Islam on smoking among Muslims. BMJ 2006;332:291-4.

3. Radwan GN, Israel E, El-Setouhy M, et al. Impact of religious rulings (fatwa) on smoking. J Egypt Soc Parasitol 2003;33(3 Suppl):1087-101.

4. El Awa F. Middle East: religion against tobacco. Tob Control 2003:12:249-50.

5. Sucakli MH, Ozer A, Celik M, et al. Religious officials' knowledge, attitude, and behavior towards smoking and the new tobacco law in Kahramanmaras, Turkey. BMC Public Health 2011;11:602.

6. Garrusi B, Nakhaee N. Religion and smoking: a review of recent literature. Int J Psychiatry Med 2012;43:279-92.

7. Swaddiwudhipong W, Chaovakiratipong C, Nguntra P, et al. A Thai monk: an agent for smoking reduction in a rural population. Int $J$ Epidemiol 1993;22:660-5.

8. Tahlil T, Woodman RJ, Coveney J, et al. The impact of education programs on smoking prevention: a randomized controlled trial among 11 to 14 year olds in Aceh, Indonesia. BMC Public Health 2013;13:367. 
9. Voorhees CC, Stillman FA, Swank RT, et al. Heart, body, and soul: impact of church-based smoking cessation interventions on readiness to quit. Prev Med 1996;25:277-85.

10. Yong HH, Savvas S, Borland R, et al. Secular versus religious norms against smoking: which is more important as a driver of quitting behaviour among Muslim Malaysian and Buddhist Thai smokers? Int J Behav Med 2013;20:252-8.

11. Neighbors $\mathrm{C}$, LaBrie JW, Hummer JF, et al. Group identification as a moderator of the relationship between perceived social norms and alcohol consumption. Psychol Addict Behav 2010;24:522-8.

12. Merton RK, Rossi AS. Contributions to the theory of reference group behavior. In: Merton R, ed. Social theory and social structure. Rev. and enl. ed. New York: Free Press, 1968:229-35.

13. Bock EW, Beeghley L, Mixon AJ. Religion, socioeconomic status, and sexual morality: an application of reference group theory. Socio Q 1983;24:545-59.

14. Yong HH, Hamann SL, Borland R, et al. Adult smokers' perception of the role of religion and religious leadership on smoking and association with quitting: a comparison between Thai Buddhists and Malaysian Muslims. Soc Sci Med 2009;69:1025-31.

15. El Awa F. The role of religion in tobacco control interventions. Bull World Health Organ 2004;82:894.

16. Indonesia Badan Pusat Statistik [Indonesian Central Bureau of Statistics]. Penduduk menurut wilayah dan agama yang dianut [Population by region and religious affiliation]. Secondary Penduduk menurut wilayah dan agama yang dianut [Population by region and religious affiliation] 2010. http://sp2010.bps.go.id/index.php/site/ tabel?tid=321\&wid=0 (accessed 24 May 2013).

17. Bachyul S, Maulia E. MUI edicts condemned as 'pointless'. Jakarta Post 2009 January 27. http://www.thejakartapost.com/news/2009/01/ 27/mui-edicts-condemned-039pointless039.htm

18. Islamic scholars challenge MUI edicts on smoking and yoga. Jakarta Post 2009 January 26. http://www.thejakartapost.com/news/2009/01/ 26/islamic-scholars-challenge-mui-edicts-smoking-and-yoga.htm

19. Sagita D. Reluctance on tobacco rules puts lives at risk. Jakarta Globe 2013 October 22. http://thejakartaglobe.beritasatu.com/news/ reluctance-on-tobacco-rules-puts-lives-at-risk

20. Hapsari AD. Muhammadiyah declares smoking to be haram. Jakarta Post 2010 March 10. http://www.thejakartapost.com/news/2010/03/ 10/muhammadiyah-declares-smoking-be-haram.html
21. WHO. Global Adult Tobacco Survey: Indonesia report 2011. New Delhi: World Health Organization Regional Office for Southeast Asia, 2012.

22. Hurt RD, Ebbert JO, Achadi A, et al. Roadmap to a tobacco epidemic: transnational tobacco companies invade Indonesia. Tob Control 2012;21:306-12.

23. Tentang Kawasan Tanpa Rokok [On Area Without Smoke] Peraturan Daerah Kota Bogor Nomor 12 Tahun 2009 [Regional Regulation Bogor City Number 12 Year 2009]. Secondary Tentang Kawasan Tanpa Rokok [On Area Without Smoke]. Peraturan Daerah Kota Bogor Nomor 12 Tahun 2009 [Regional Regulation Bogor City Number 12 Year 2009]. http://siskum.kotabogor.go.id/index.php/ peraturan-daerah/finish/12-perda-2009/57-perda-no12-tahun-2009 (accessed 4 Oct 2014).

24. Bogor Smoke-Free NGO Alliance, Bogor City Health Office. Compliance study in Bogor. Bogor, Indonesia, 2011.

25. Hussain Z. Indonesian Muslim body celebrates 100 years, stays true to moderate roots. Jakarta Globe 2012 November 19. http://www. thejakartaglobe.com/archive/indonesian-muslim-body-celebrates100-years-stays-true-to-moderate-roots/

26. Harper D. Talking about pictures: a case for photo elicitation. Vis Stud 2002;17:13-26.

27. Green J, Thorogood N. Qualitative methods for health research. 2nd edn. Los Angeles: SAGE, 2009.

28. Byron MJ. Understanding secondhand smoke laws in high-prevalence LMIC's: early findings from Indonesia [conference poster]. 19th Annual Meeting of the Society for Research on Nicotine and Tobacco; Boston, MA, 2013.

29. Maxwell JA. Qualitative research design: an interactive approach 2nd edn. Thousand Oaks, CA: Sage, 2005.

30. Eriksen M, Mackay J, Ross H. The tobacco atlas. 4th edn. Atlanta, GA: American Cancer Society, 2012.

31. Burhani AN. Defining Indonesian Islam: an examination of the construction of the national Islamic identity of traditionalist and modernist Muslims. In: Burhanudin J, van Dijk K, eds. Islam in Indonesia, contrasting images and interpretations. Amsterdam: Amsterdam University Press, 2013:25-48.

32. Nichter M, Padmawati S, Danardono M, et al. Reading culture from tobacco advertisements in Indonesia. Tob Control 2009;18:98-107. 